\title{
Experimental reproduction of bluetongue virus serotype 8 clinical disease in calves
}

\author{
F. Dal Pozzo a,b, K. De Clercq ${ }^{\text {c }}$, H. Guyot ${ }^{\text {d }}$, E. Vandemeulebroucke ${ }^{c}$, \\ P. Sarradin ${ }^{\text {e }}$, F. Vandenbussche ${ }^{\text {c }}$, E. Thiry ${ }^{\text {b }}$, C. Saegerman ${ }^{\text {a,* }}$ \\ a Department of Infectious and Parasitic Diseases, Epidemiology and Risk Analysis Applied to Veterinary Sciences, Faculty of Veterinary Medicine, \\ University of Liège, Boulevard de Colonster, 20, B42, B-4000 Liège, Belgium \\ ${ }^{\mathrm{b}}$ Department of Infectious and Parasitic Diseases, Virology and Viral Diseases, Faculty of Veterinary Medicine, University of Liege, B-4000 Liège, Belgium \\ ${ }^{\mathrm{c}}$ Veterinary and Agrochemical Research Centre, Virology Department, Section of Epizootic Diseases, Groeselenberg 99,1180 Brussels, Belgium \\ ${ }^{\mathrm{d}}$ Clinical Department of Production Animals, Clinic for Ruminants, Faculty of Veterinary Medicine, University of Liege, B-4000 Liege, Belgium \\ ${ }^{\mathrm{e}}$ INRA UE 1277, Plate-forme d'Infectiologie Experimentale, 37380 Nouzilly, France
}

\section{A R T I C L E I N F O}

\section{Article history:}

Received 11 July 2008

Received in revised form 14 November 2008

Accepted 20 November 2008

\section{Keywords:}

Bluetongue virus

Serotype 8

Cattle

Experimental infection

Clinical signs

Pathogenesis

\begin{abstract}
A B S T R A C T
Cattle are commonly subclinically infected following natural or experimental infection with bluetongue virus (BTV). The introduction of BTV serotype 8 (BTV-8) in Europe has been characterized by the manifestation of clinical signs in infected cattle. In order to study the pathogenesis of BTV-8 in this host, an animal model able to reproduce the clinical manifestations of the disease is required. In this work, two calves were subcutaneously and intravenously injected with a low passage cell-adapted strain of BTV8. Both calves showed typical bluetongue clinical signs, including pyrexia, ocular discharge, conjunctivitis, oral mucosal congestion, development of ulcers and necrotic lesions on the lips and tongue, submandibular oedema, coronitis and oedema of the coronet and pastern region. A score was assigned depending on the severity of the lesions and a total clinical score was calculated for each animal daily and at the end of the experiment. Both calves became viraemic $24 \mathrm{~h}$ post-infection and seroconversion occurred between 7 and 11 days P.I.

In this study we present the development of a protocol of infection in calves able to reproduce the severity of the lesions observed with BTV-8 in field conditions.
\end{abstract}

(c) 2008 Elsevier B.V. All rights reserved.

\section{Introduction}

Bluetongue virus (BTV) is an arthropod-borne pathogen infecting most species of domestic and wild ruminants and causing high economical loss in the international movement and animal trade (MacLachlan and Osburn, 2006). BTV belongs to the genus Orbivirus within the family Reoviridae, and at present 24 serotypes have been identified (Mellor and Wittmann, 2002). Clinical signs commonly occur in sheep, while goats and cattle remain

\footnotetext{
* Corresponding author. Tel.: +32 436645 79; fax: +32 43664261 . E-mail address: claude.saegerman@ulg.ac.be (C. Saegerman).
}

mostly subclinically infected (Osburn, 1994). Although the pathogenesis of bluetongue is similar in sheep and cattle (MacLachlan et al., 1990), it is uncertain as to why BTV infection causes extensive microvascular injury in sheep, but less in cattle. Recently the role of species-specific endothelial cell-derived inflammatory and vasoactive mediators has been shown (DeMaula et al., 2002).

Since the summer 2006, BTV serotype 8 (BTV-8) appeared in northern and central Europe with striking epidemiological aspects, like the higher proportion of cattle showing clinical signs and the involvement of new Culicoides vectors during viral transmission (Saegerman et al., 2008a). During the 2006-2007 outbreaks of BTV-8 in northern and central Europe (Toussaint et al., 2007b), 
infected adult cattle showed the following clinical signs: ulcerative and necrotic lesions on the muzzle and in the oral cavity, conjunctivitis, lacrimation, periocular dermatitis, photosensitivity-like lesions, drop in milk production, loss of body condition, ulcerative and necrotic lesions on the teats, udder and vulva, oedema of the distal limbs (Thiry et al., 2006; Guyot et al., 2007; Elbers et al., 2008). In Europe BTV-8 appeared to cause transplacental infection, which was normally associated until now to live BTV strains adapted in cell culture (MacLachlan et al., 2000; Vercauteren et al., 2008; Wouda et al., 2008).

The understanding of the viral pathogenesis in cattle during BTV-8 infection is still rather poor. There is a real need of a reliable and reproducible experimental model to study the viral-host interactions, including the development of clinical signs associated to the infection. Many experimental inoculation studies have been conducted to characterize BTV pathogenesis in cattle, including a variety of serotypes, animals of different ages and various methods of inoculation. At present, only one study has been published with BTV-8 experimental infected sheep and cattle, where the latter did not show obvious clinical manifestations of the disease, although the necropsy revealed a generalized lymphadenopathy and, only in one cattle, petechial haemorrhages on several organs (Darpel et al., 2007).

The aim of our study was to reproduce, in experimentally infected calves, the clinical signs of the disease observed in naturally infected cattle with BTV-8. The results obtained infecting two calves with BTV-8 are presented, with particular emphasis to the characterization and quantification of the different clinical signs observed during the experiment.

\section{Materials and methods}

\subsection{Animals}

Two 5 months old female Holstein calves have been used in this study (calf 3179 and 3181). The animals were bought from a French farm located in a BTV-free area and being regularly monitored for BTV. Before the beginning of the experiment, the calves and their dams were tested to confirm their seronegative and non-viraemic status for BTV. Furthermore, they have been also tested for bovine viral diarrhea virus (BVDV) (IDEXX HerdChek, Bovine Viral Diarrhea Virus Ab; LSI, Kit TaqVet BVD) and infectious bovine rhinotracheitis (IBR) with negative results. A veterinarian was attesting the healthy conditions of the selected calves after a detailed clinical examination.

\subsection{Virus}

Bluetongue virus serotype 8 (BTV-8) strain BEL2006/01 P2, isolated during the 2006 epidemic season in Belgium, was used (Toussaint et al., 2007b). First the virus was isolated from the EDTA-blood on embryonated chicken eggs, and subsequently propagated on BHK-21 cell culture. The second passage of the virus on BHK-21 cells had a titer of $10^{5.3} \mathrm{TCID}_{50} / \mathrm{ml}$ and it was used as inoculum in our experimental protocol.

\subsection{Experimental design}

The experimental infection was performed during the winter season, when the vector activity was reduced. The calves were confined in an insect-secure zone at the Experimental Infectiology Platform (PFIE) of the INRA centre of Tours (Nouzilly, France) and insects light traps were installed at the entrance of the experimental area. During the experiments, animals were treated following the International Guiding Principles for Biomedical Research Involving Animals as issued by the Council for the International Organizations of Medical Sciences. Both calves have been infected using BTV-8 strain BEL2006/01 P2. The infection has been performed in the neck using $2 \mathrm{ml}$ of viral inoculum. The dose was administered $1 \mathrm{ml}$ subcutaneously (SC) and $1 \mathrm{ml}$ intravenously (IV). After 14 days post-infection, animals were euthanized following an IV injection of pentobarbital. Spleen, prescapular and medistinic lymph nodes, tongue were collected from both animals and stored at $-80^{\circ} \mathrm{C}$ for viral RNA detection.

\subsection{Clinical examination}

The animals were monitored daily by a veterinarian for the duration of the experiment ( 15 days). The body temperature and the development of clinical signs were examined daily at the same moment of the day (in the morning) (Jackson and Cockcroft, 2002), and a digital camera was used to record the evolution of the lesions. A standardized clinical form for BTV infection was used during the animal examination, in order to analyse systematically the most affected organs and systems (Saegerman et al., $2008 \mathrm{~b}$ ). In the daily clinical examination, we proceeded in the methodological differentiation of general and specific clinical signs. A major attention was orientated to the skin and the visible mucous membranes, to the locomotor, digestive, respiratory and nervous systems. In addition, for clinical data, a score was attributed for each observed clinical sign in order to quantify the severity of the lesion, and the score of an individual calf was defined as the sum of all clinical signs present. A total clinical score was calculated for each animal daily, at the end of the experiment and also for each group of clinical signs.

\subsection{Laboratory analysis}

\subsubsection{Serological analysis}

For serological analysis, whole blood was collected daily. It was centrifuged at $3000 \mathrm{rpm}$ for $10 \mathrm{~min}$ and the serum was stored subsequently at $-20^{\circ} \mathrm{C}$. The ID Screen ${ }^{\mathbb{R}}$ Bluetongue Competition ELISA kit (ID VET, Montpellier, France) was used to detect the appearance of antibodies directed against BTV. The cELISA was performed following manufacturer's instructions. Besides the kit controls, a twofold dilution series of an anti-BTV antibody positive reference serum was included and the results were expressed as \% negativity (PN) as described by Vandenbussche et al. (2008).

\subsubsection{BTV detection in biological samples}

EDTA-blood samples were collected daily and stored at $+4{ }^{\circ} \mathrm{C}$. These samples were used to detect the levels of 
viraemia by real-time RT-PCR (RT-qPCR) according to Vandenbussche et al. (2008). In order to amplify BTV genome, a RT-qPCR amplifying a region of BTV segment 5 (RT-qPCR_S5) was used (Toussaint et al., 2007a). Bovine beta-actin was contemporarily amplified as internal control (Toussaint et al., 2007a). Cycle threshold values $(\mathrm{Ct})$ for each sample were used to compare the daily blood viral load.

BTV detection by RT-qPCR was also performed from spleen, tongue, prescapolar and mediastinic lymph nodes collected during necropsy and stored at $-80^{\circ} \mathrm{C}$. Starting from $100 \mathrm{mg}$ of tissue, the RNA was extracted using TrizolLS reagent (Gibco, Invitrogen). BTV and beta-actin RT-qPCR were performed as described above.

\subsection{Statistical analysis}

The trends of clinical pattern in time and by group of clinical signs were compared by using Spearman's rank correlation, called $r_{\mathrm{s}}$ in the text (Dagnelie, 1998). A $P$ value $<0.05$ was considered as significant.

\section{Results and discussion}

In this study we describe for the first time the occurrence of clinical signs in calves experimentally infected with BTV-8. In the Bluetongue chapter of the OIE Terrestrial Manual 2008, the use of wild type virus with no ECE or cell culture passages is recommended during the challenge of vaccinated animals in order to test the efficacy of the vaccine. The two calves included in the study received a subcutaneous and an intravenous injection of a BTV-8 strain with only two passages on BHK-21 cell culture and with a high viral titer. The intravenous injection of a virulent BTV strain is probably at the origin of the successful reproduction of the severe clinical signs that have been observed in the field. Recently severe bluetongue disease has been experimentally induced in sheep using BTV-4 with the intravenous injection of infectious blood (MacLachlan et al., 2008). The possibility to reproduce the clinical manifestations associated to BTV infection seems to be highly increased by the use of a virulent strain inoculated intravenously. The accuracy and reproducibility of the described experimental protocol will be evaluated using a larger number of infected animals and taking into account the kind of inoculum.

The clinical consequences observed in the two calves were not dissimilar to the signs induced spontaneously by BTV-8. The day after the infection the calves had pyrexia, a sign which has been already observed in previous experimental infection with BTV (Odeón et al., 1997; Darpel et al., 2007). Probably related to the high levels of viraemia of the following days, we measured a slight increase in body temperature between 7 and 10 days P.I. The daily body temperature, expressed in ${ }^{\circ} \mathrm{C}$ and recorded in the two calves during the experiment, is shown in Fig. 1A. Since the first day P.I., a bilateral aqueous ocular discharge developed in calf 3179 . In the following days, the ocular discharge progressively became abundant, with a mucus-purulent feature (Fig. 2A), associated to a bilateral
(A)

Day post-infection

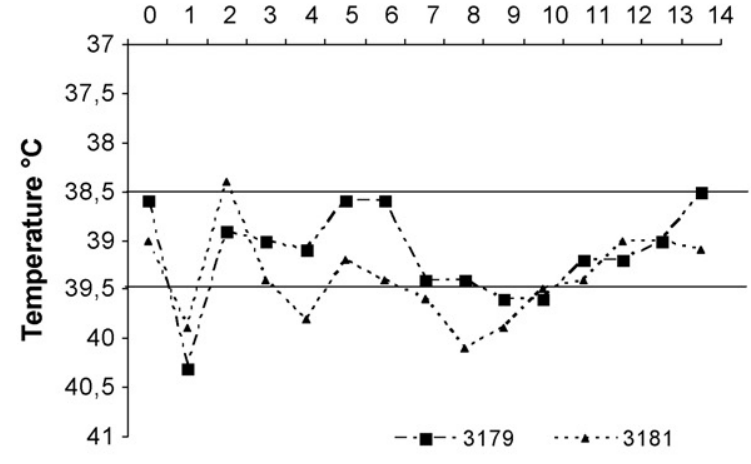

calf 3179

(B)

Day post-infection

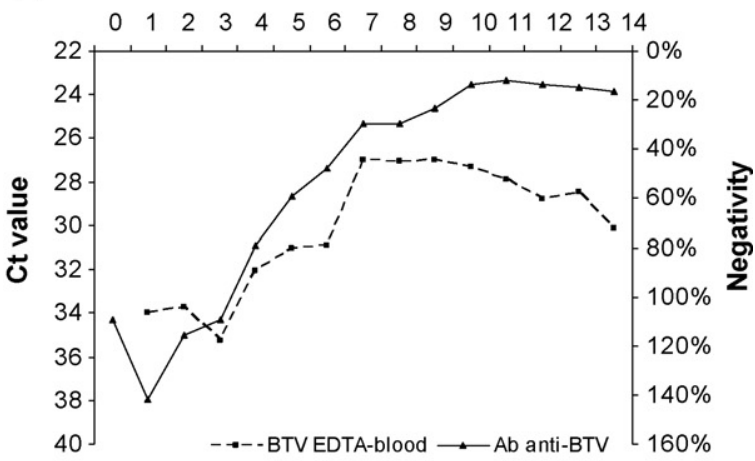

(C)

calf 3181

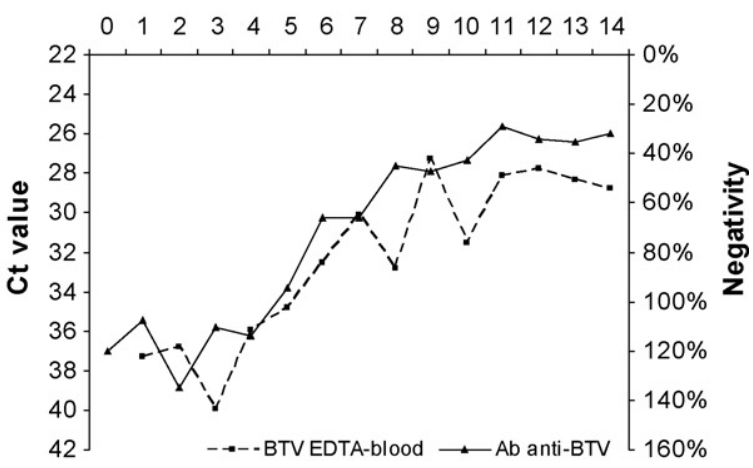

Fig. 1. The variation of the body temperature of calf 3179 and 3181 during the experimental infection with BTV-8 is shown in (A). The two black horizontal lines delimit the physiological body temperature range in calves (between $38.5^{\circ} \mathrm{C}$ and $39.5^{\circ} \mathrm{C}$ ). (B) and (C) Illustration of the antibody response and the dynamic of viraemia in calf 3179 and 3181 , respectively. The results of the serological analysis are expressed as \% of negativity and were calculated referring to the negative control. BTV detection in EDTA-blood was performed by RT-qPCR and the results were expressed in $\mathrm{Ct}$ values.

conjunctivitis since 3 days P.I. (Fig. 2B). An enhanced bilateral mucous ocular discharge was observed starting from 12 days P.I. In calf 3181 the appearance of the ocular discharge started since 4 days P.I. and it was complicated by conjunctivitis at 10 days P.I. After 4 days P.I. and for the 
(A)

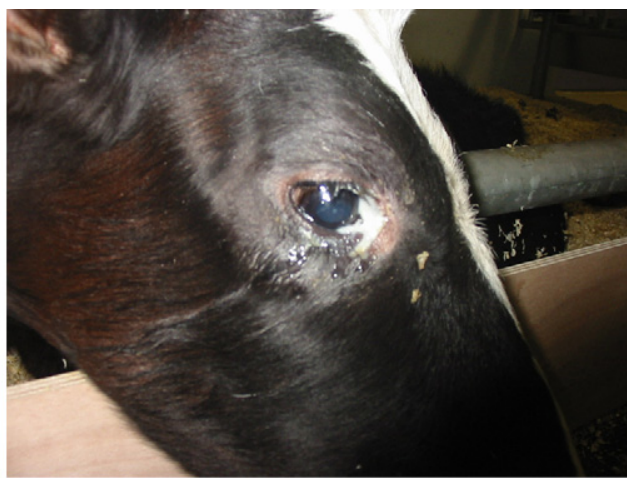

(C)

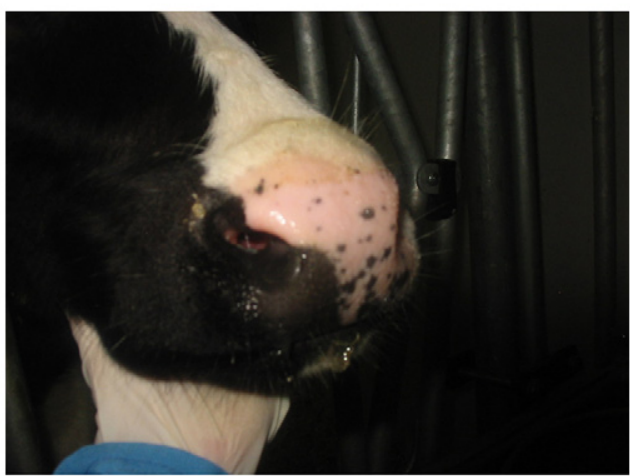

(E)

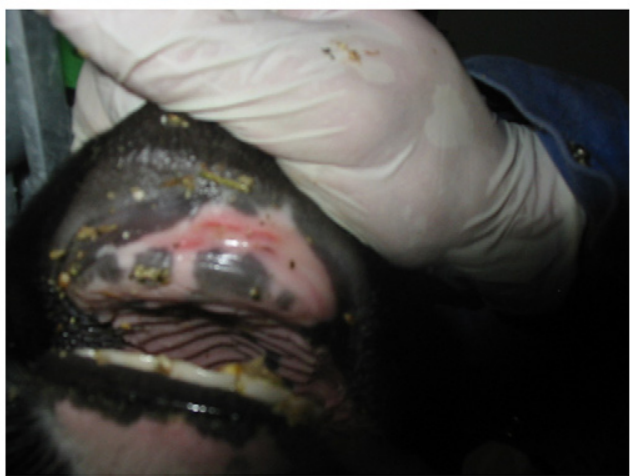

(B)

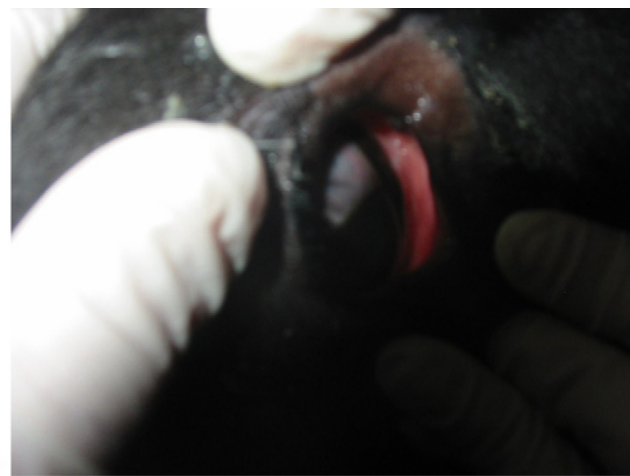

(D)

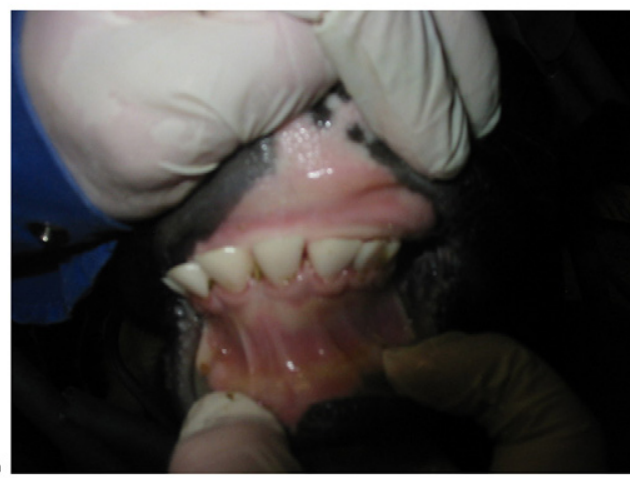

(F)

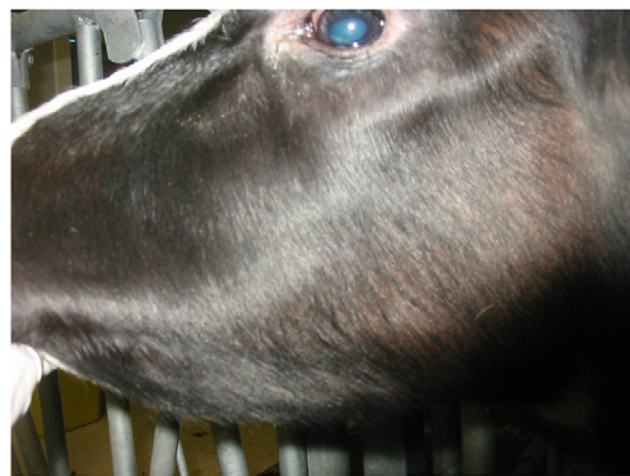

Fig. 2. (A) The severity of the ocular discharge observed in calf 3179 after 4 days PI. After 3 days P.I. a remarkable conjunctivitis was observed in calf 3179 (B). (C) Illustration of the nasal discharge observed in calf 3181 . A diffused oral congestion was observed already 2 days P.I. in calf 3179 while the first multiple oral erosions appeared in the inner part of the above lip after 4 days P.I. ((D) and (E), respectively). (F) Submandibular oedema observed 6 days post-infection in calf 3179

entire duration of the observation, calf 3181 had an increased nasal discharge, although it conserved a physiological watery feature (Fig. 2C). No sign of dyspnea was observed in both calves. In calf 3179 a diffuse congestion of the oral mucosa was observed already 2 days P.I., and multiple erosions appeared in the inner part of the upper lip 4 days P.I. (Fig. 2D and E). The lesions were associated with a congestion of the gum and the oral mucosa of the inner lips. These erosions healed within some days with the development of a scab 9 days P.I. Four new smaller ulcers appeared 10-11 days P.I. These ulcers were round and localized at the junction of the oral mucosa and the skin at the right and left side of the lower and upper lip. A generalized congestion of the gums and of the oral mucosa was observed 5 days P.I. in calf 3181 . The first oral ulcers in this animal appeared 11 days P.I. and their localization and aspect were very similar to the lesions described in calf 3179 at the same time of the infection. Viral replication in the mouth was underlined by BTV RNA detection in the tongue of both calves (data not shown). This finding and the continuous generation of new lesions in the oral cavity underlined the active in situ replication of the virus. The importance of the oral cavity as a privileged localization during viral pathogenesis was furthermore underlined by the high scores attributed to the oral lesions developed by both calves (Table 1 ). The frequent appearance of oral clinical signs during spontaneous bluetongue disease in cattle was already reported (Saegerman et al., 2007; Elbers et al., 2008).

Starting from 6 days P.I., a characteristic submandibular oedema appeared in both animals (Fig. 2F). No other oedemas were detected in the different regions of the head 
Table 1

Clinical scores applied to BTV-8 induced lesions observed in calf 3179 and 3181.

\begin{tabular}{|c|c|c|c|c|c|c|c|c|c|c|c|c|c|c|c|c|}
\hline & \multicolumn{15}{|c|}{ Days post-infection } & \multirow[t]{2}{*}{ Total score } \\
\hline & 0 & 1 & 2 & 3 & 4 & 5 & 6 & 7 & 8 & 9 & 10 & 11 & 12 & 13 & 14 & \\
\hline \multicolumn{17}{|c|}{ Body temperature $^{a}$} \\
\hline 3179 & 0 & 2 & 0 & 0 & 0 & 0 & 0 & 0 & 0 & 1 & 1 & 0 & 0 & 0 & 0 & 4 \\
\hline 3181 & 0 & 1 & 0 & 0 & 1 & 0 & 0 & 1 & 2 & 1 & 0 & 0 & 0 & 0 & 0 & 6 \\
\hline \multicolumn{17}{|c|}{ Ocular signs ${ }^{\mathrm{b}}$} \\
\hline 3179 & 0 & 1 & 1 & 2 & 2 & 2 & 1 & 1 & 1 & 0 & 0 & 0 & 1 & 2 & 1 & 15 \\
\hline 3181 & 0 & 0 & 0 & 0 & 1 & 1 & 1 & 1 & 1 & 1 & 2 & 2 & 0 & 0 & 0 & 10 \\
\hline \multicolumn{17}{|c|}{ Oral lesions ${ }^{c}$} \\
\hline 3179 & 0 & 0 & 0 & 0 & 3 & 3 & 3 & 3 & 3 & 1 & 3 & 3 & 3 & 3 & 3 & 31 \\
\hline 3181 & 0 & 0 & 0 & 0 & 0 & 1 & 1 & 1 & 1 & 1 & 1 & 3 & 3 & 3 & 3 & 18 \\
\hline \multicolumn{17}{|c|}{ Lesions to the locomotor system ${ }^{d}$} \\
\hline 3179 & 0 & 0 & 0 & 0 & 0 & 1 & 1 & 1 & 2 & 2 & 2 & 2 & 2 & 2 & 2 & 17 \\
\hline 3181 & 0 & 0 & 0 & 0 & 0 & 0 & 0 & 1 & 1 & 1 & 2 & 2 & 2 & 2 & 2 & 13 \\
\hline \multicolumn{17}{|c|}{ Oedema $^{\mathrm{e}}$} \\
\hline 3179 & 0 & 0 & 0 & 0 & 0 & 0 & 1 & 1 & 1 & 1 & 1 & 1 & 1 & 1 & 1 & 9 \\
\hline 3181 & 0 & 0 & 0 & 0 & 0 & 0 & 1 & 1 & 1 & 1 & 1 & 1 & 1 & 1 & 1 & 9 \\
\hline \multicolumn{17}{|c|}{ Total clinical score ${ }^{f}$} \\
\hline 3179 & 0 & 3 & 1 & 2 & 5 & 6 & 6 & 6 & 7 & 5 & 7 & 6 & 7 & 8 & 7 & 76 \\
\hline 3181 & 0 & 1 & 0 & 0 & 2 & 2 & 3 & 5 & 6 & 5 & 6 & 8 & 6 & 6 & 6 & 56 \\
\hline
\end{tabular}

${ }^{\text {a }}$ Body temperature score: 0 (body temperature $\leq 39.5^{\circ} \mathrm{C}$ ), 1 (body temperature $\geq 39.6{ }^{\circ} \mathrm{C} \leq 39.9{ }^{\circ} \mathrm{C}$ ), 2 (body temperature $\geq 40{ }^{\circ} \mathrm{C}<41{ }^{\circ} \mathrm{C}$ ), and $3($ body temperature $>41^{\circ} \mathrm{C}$ ).

b Ocular lesions score: 0 (absence of ocular clinical signs), 1 (ocular discharge), 2 (conjunctivitis was contemporarily observed), and 3 (with complicated ocular dermatitis).

c Oral lesions score: 0 (absence of clinical signs), 1 (mucosal congestion), 2 (presence of one oral erosion or one ulcer), and 3 (multiple erosions or ulcers). In the presence of a scab as a consequence of the healing process, a score of 1 was attributed.

d Locomotor system score: 0 (absence of clinical signs), 1 (congestion of the coronary band), 2 (congestion and oedema), and 3 (lameness).

e Oedema score: 0 (absence of oedemas), 1 (1 oedema), 2 (with 2 oedemas), and 3 (multiple oedemas localized in different regions).

f Total daily clinical score.

or in other body areas. Coronitis was detected in both calves 1 week after the infection. This lesion started with a reddening around the coronary band at 5 days postinfection (Fig. 3A), followed by an aggravation of the inflammation and the addition of a localized oedema in the coronet and pastern region at 8-9 days post-infection (Fig. 3B-D). No one of the calves showed lameness or difficulties in standing up, but the presence of a rubber carpet was probably reducing the pain during the contact of the feet on the ground.

A total daily clinical score was calculated for each animal and it allowed appreciating the progression of the disease (Table 1). The calves had few or unapparent clinical signs the first 3 days P.I., while starting from the 4th day, the infection became clinically manifest. Since day 7 P.I., the severity of the disease enhanced with the development of multiple clinical signs: ocular discharge and conjunctivitis, ulcers in the oral mucosa, lesions in the coronet and pastern region and submandibular oedema (Table 1). In addition, a very good correlation was observed between the two calves for daily total score and total score by group of clinical signs $\left(r_{\mathrm{s}}=0.86\right.$ and 1 , respectively; $\left.P<0.0001\right)$ indicating a highly similar clinical pattern in the two calves.

The development of viraemia and the seroconversion of the inoculated calves represent evidences of the occurred infection (Fig. 1B and C). BTV RNA was amplified in every EDTA-blood samples starting from $24 \mathrm{~h}$ postinfection. Since 4 day P.I., the Ct values progressively decreased, showing a constant increment of the viral RNA load in the blood of the two calves (Fig. 1B and C). The quantification of the BTV genome in the blood of the two calves, allowed us to follow the dynamic of the viraemia. The early detection of the viral RNA in the blood after $24 \mathrm{~h}$ post-infection was probably due to the intravenous injection of the virus. The temporary reduction of the viral RNA load in the blood stream until the third day P.I., was probably to refer to the distribution of the virus to the sites of primary and secondary replication, such as lymph nodes, and spleen. Lymphoid organs are important sides of viral replication in sheep and cattle (MacLachlan et al., 1990). The subsequent increase of the viraemia 4 days P.I., was probably to refer to the transit of the virus from the sites of massive replication to the blood stream. In the literature for other BTV serotypes, it is reported that in cattle the release of BTV from the spleen is followed by high titer viraemia which persists for several weeks postinfection (MacLachlan et al., 1990). After 14 days P.I., the virus was detected by RT-qPCR in the spleen and the tongue of both animals, while the tested lymph nodes were negative (data not shown). These results are probably explained by the fugacity of the viral replication in the lymph nodes during the earliest phase of the infection, and by the longer persistence of the virus in the spleen. Similar findings were previously observed in intravenously infected calves (MacLachlan et al., 1990, 2008).

The development of clinical signs in cattle infected with BTV-8 is atypical because the disease in this animal host is more commonly undetectable. Before the outbreak 
(A)

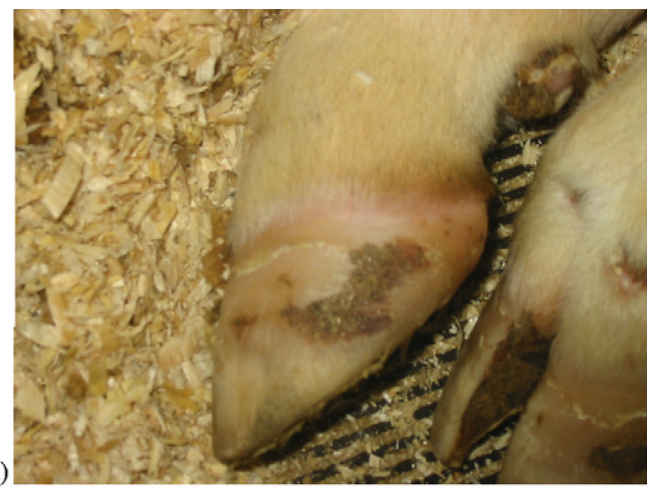

(C)

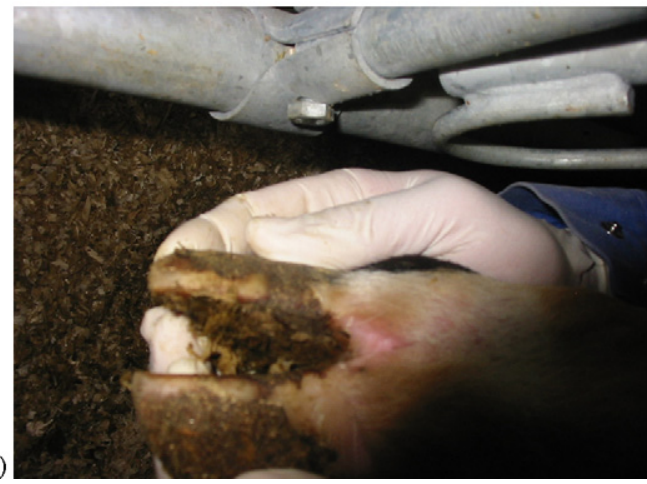

(B)

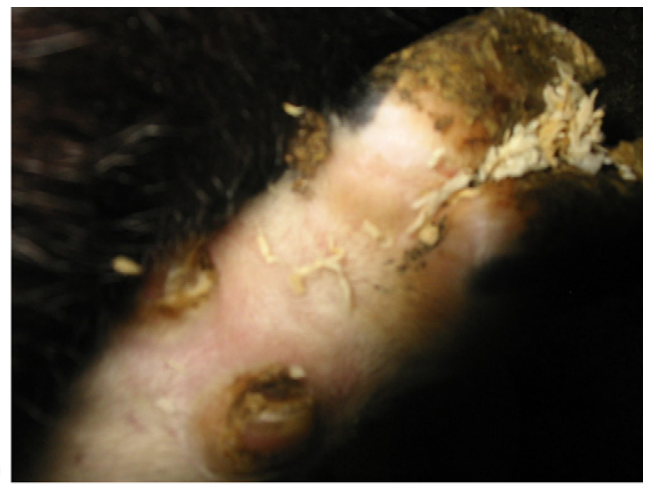

(D)

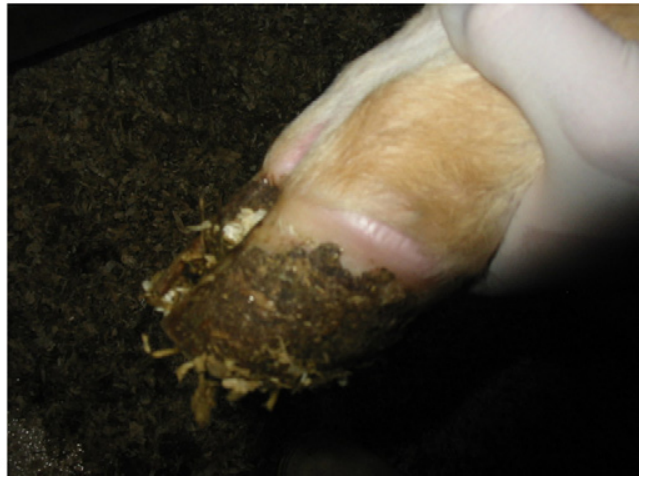

Fig. 3. After 5-6 days post-infection, we observed reddening of the coronary band (A), followed by reddening and oedema in the coronet and pastern region at 8-9 days post-infection (B)-(D).

of BTV-8 in Europe, some authors have suggested that the rare clinical manifestations in cattle could be explained by a hypersensitivity reaction and to the development of IgEspecific antibody to BTV (Anderson et al., 1985). At present no evidences of the involvement of an immunopathological reaction in the development of the lesions showed by cattle infected with BTV-8, have been documented. The mechanisms explaining the severity of the lesions produced by BTV-8 in cattle have to be investigated. In particular, increased host susceptibility and higher virulence of BTV- 8 are the factors to be elucidated. The availability of a model to characterize bluetongue disease in cattle will be crucial for future investigations. The experimental protocol presented in this study successfully reproduced the lesions observed in naturally infected cattle and confirmed the severity of the clinical signs induced by BTV-8 in northern Europe.

\section{Acknowledgements}

This research was funded by the Federal Public Service Health, Food Chain Safety and Environment (contrat RF 6190), Brussel, Belgium and by the "Fonds spéciaux pour la Recherche-Crédit classique" (contrat C-06/02), University of Liège, Belgium. A great assistance in the serological analysis was obtained from Bart Verheyden (Veterinary and Agrochemical Research Centre, Brussel, Belgium). The authors thank staff members of the Plate-forme d'Infectiologie Experimentale (INRA, Tours). A special acknowl- edgment goes to Dominique Ziant and Lorène Dams for their technical support.

\section{References}

Anderson, G.A., Stott, J.L., Gershwin, L.J., Osburn, B.I., 1985. Subclinical and clinical bluetongue disease in cattle: clinical, pathological and pathogenic considerations. Prog. Clin. Biol. Res. 178, 103-107.

Dagnelie, P., 1998. Interférence statistique à une et à deux dimensions. Statistique théorique et appliquée, vol. 2. De Boeck \& Larcier, Paris.

Darpel, K.E., Batten, C.A., Veronesi, E., Shaw, A.E., Anthony, S., BachanekBankowska, K., Kgosana, L., bin-Tarif, A., Carpenter, S., Müller-Doblies, U.U., Takamatsu, H.H., Mellor, P.S., Mertens, P.P., Oura, C.A., 2007. Clinical signs and pathology shown by British sheep and cattle infected with bluetongue virus serotype 8 derived from the 2006 outbreak in northern Europe. Vet. Rec. 161 (8), 253-261.

DeMaula, C.D., Leutenegger, C.M., Bonneau, K.R., MacLachlan, N.J., 2002 The role of endothelial cell-derived inflammatory and vasoactive mediators in the pathogenesis of bluetongue. Virology 296 (2), 330-337.

Elbers, A.R., Backx, A., Ekker, H.M., van der Spek, A.N., van Rijn, P.A., 2008. Performance of clinical signs to detect bluetongue virus serotype 8 outbreaks in cattle and sheep during the 2006-epidemic in the Netherlands. Vet. Microbiol. 129 (1-2), 156-162.

Guyot, H., Mauroy, A., Thiry, E., Losson, B., Bodmer, M., Kirten, P., Rollin, F., Saegerman, C., 2007. Description clinique des cas de FCO survenus au Nord de l'Europe durant l'été et l'automne 2006. Bull. GTV 39, 89-96.

Jackson, P., Cockcroft, P.D., 2002. Clinical Examination of Farm Animals. Blackwell Science Ltd., Oxford, United Kingdom.

MacLachlan, N.J., Osburn, B.I., 2006. Impact of bluetongue virus infection on the international movement and trade of ruminants. J. Am. Vet. Med. Assoc. 228 (9), 1346-1349.

MacLachlan, N.J., Conley, A.J., Kennedy, P.C., 2000. Bluetongue and equine viral arteritis viruses as models of virus-induced fetal injury and abortion. Anim. Reprod. Sci. 60-61, 643-651.

MacLachlan, N.J., Crafford, J.E., Vernau, W., Gardner, I.A., Goddard, A., Guthrie, A.J., Venter, E.H., 2008. Experimental reproduction of severe bluetongue in sheep. Vet. Pathol. 45 (3), 310-315. 
MacLachlan, N.J., Jagels, G., Rossitto, P.V., Moore, P.F., Heidner, H.W., 1990. The pathogenesis of experimental bluetongue virus infection of calves. Vet. Pathol. 27 (4), 223-229.

Mellor, P.S., Wittmann, E.J., 2002. Bluetongue virus in the Mediterranean Basin 1998-2001. Vet. J. 164 (1), 20-37.

Odeón, A.C., Schore, C.E., Osburn, B.I., 1997. The role of cell-mediated immunity in the pathogenesis of bluetongue virus serotype 11 in the experimental infection of vaccine/sensitized calves. Comp. Immunol. Microbiol. Infect. Dis. 20 (3), 219-231.

Osburn, B.I., 1994. Bluetongue virus. Vet. Clin. N. Am. Food. Anim. Pract. 10 (3), 547-560.

Saegerman, C., Mauroy, A., Guyot, H., Rollin, F., Losson, B., Vandenbussche, F., Vanbinst, T., De Clercq, K., Thiry, E., 2007. Clinical aspects linked with the emergence of bluetongue in cattle in northern Europe: results of a two month longitudinal study. Renc. Rech. Ruminants 14, 215.

Saegerman, C., Berkvens, D., Mellor, P.S., 2008a. Bluetongue epidemiology in the European union. Emerg. Infect. Dis. 14 (4), 539-544.

Saegerman, C., Mauroy, A., Guyot, H., 2008b. Bluetongue in ruminants: a standardised clinical report form for the use in different species. In: Saegerman, C., Reviriego-Gordejo, F., Pastoret, P.P. (Eds.), Bluetongue in Northern Europe. OIE Publication, Paris, pp. 82-87.

Thiry, E., Saegerman, C., Guyot, H., Kirten, P., Losson, B., Rollin, F., Bodmer, M., Czaplicki, G., Toussaint, J.F., De Clercq, K., Dochy, J.M., Dufey, J.,
Gilleman, J.L., Messeman, K., 2006. Bluetongue in northern Europe. Vet. Rec. 159 (10), 327.

Toussaint, J.F., Sailleau, C., Breard, E., Zientara, S., De Clercq, K., 2007a. Bluetongue virus detection by two real-time RT-qPCRs targeting two different genomic segments. J. Virol. Methods 140 (1-2), 115-123.

Toussaint, J.F., Sailleau, C., Mast, J., Houdart, P., Czaplicki, G., Demeestere L., Vandenbussche, F., Van Dessel, W., Goris, N., Bréard, E., Bounaadja, L., Thiry, E., Zientara, S., De Clercq, K., 2007b. Bluetongue in Belgium, 2006. Emerg. Infect. Dis. 13, 614-616.

Vandenbussche, F., Vanbinst, T., Verheyden, B., Van Dessel, W., Demeestere, L., Houdart, P., Bertels, G., Praet, N., Berkvens, D., Mintiens, K., Goris, N., De Clercq, K., 2008. Evaluation of antibody-ELISA and realtime RT-PCR for the diagnosis and profiling of bluetongue virus serotype 8 during the epidemic in Belgium in 2006. Vet. Microbiol. $129(1-2), 15-27$.

Vercauteren, G., Miry, C., Vandenbussche, F., Ducatelle, R., Van der Heyden, S., Vandemeulebroucke, E., De Leeuw, I., Deprez, P., Chiers, K., De Clercq, K., 2008. Bluetongue virus serotype 8-associated congenital hydranencephaly in calves. Transbound. Emerg. 55 (7), 293-298.

Wouda, W., Roumen, M.P.H.M., Peperkamp, N.H.M.T., Vos, J.H., van Garderen, E., Muskens, J., 2008. Hydranencephaly in calves following the bluetongue serotype 8 epidemic in the Netherlands. Vet. Rec. 162 , 422-423. 